Tropical Journal of Pharmaceutical Research August 2012; 11 (4): 631-636

(c) Pharmacotherapy Group, Faculty of Pharmacy, University of Benin Benin City, 300001 Nigeria.

All rights reserved.

Available online at http://www.tjpr.org

Research Article

http://dx.doi.org/10.4314/tjpr.v11i4.14

\title{
Analysis of Metal Content of Samples of Gloriosa Superba L (Colchicaceae) Collected from Two Different Locations in Pakistan
}

\author{
Haroon Khan ${ }^{1,2}$, Murad Ali Khan ${ }^{3}$, Shafiq Ahmad Tariq ${ }^{4}$, Muhammad \\ Saeed $^{2}$, Naveed Muhammad ${ }^{2}$, Farah Gul ${ }^{2,5}$ and Humaira Inayat ${ }^{5}$ \\ ${ }^{1}$ Gandhara College of Pharmacy, Gandhara University, ${ }^{2}$ Department of Pharmacy, University of Peshawar, \\ Peshawar, ${ }^{3}$ Department of Chemistry Kohat University of Science and Technology, Kohat, ${ }^{4}$ Department of \\ Pharmacology, Khyber Medical University, ${ }^{5}$ Medicinal Botanic Center, PCSIR Laboratories Complex, Peshawar, \\ Pakistan
}

\begin{abstract}
Purpose: To determine the metallic content of different parts of Gloriosa superba collected from two different locations in Pakistan, and also to assess their nutritious values and toxic levels.

Methods: The plant material and soil were collected from two different locations - polluted and unpolluted. Wet digestion method was used for the preparation of samples (whole plant and soil) followed by analysis using flame atomic absorption spectrophotometer (for micronutrients) and flame photometry (for macronutrients).

Results: Of the detected micronutrients, high concentrations of $\mathrm{Zn}, \mathrm{Fe}$ and $\mathrm{Mn}$ were noted for samples collected from both areas. These values were within permissible limits. Samples collected from the polluted area contained $\mathrm{Cu}(7.5-13.0 \mathrm{ppm}), \mathrm{Cr}(1.4-1.9 \mathrm{ppm})$ and $\mathrm{Ni}(0.3-2.0 \mathrm{ppm})$, all of which exceeded acceptable limits; the same nutrients were mostly within acceptable limits for samples collected from the unpolluted area. Significant presence of macronutrients - $\mathrm{Ca}, \mathrm{Na}$ and $\mathrm{K}$ - were observed in samples obtained from both areas.

Conclusion: Proper validation of medicinal plants used for therapeutic purposes should be mandatory on safety grounds to protect consumers from contaminants.
\end{abstract}

Keywords: Gloriosa superba, Micronutrients, Macronutrients, Toxicity, Metal ions, Medicinal plants 


\section{INTRODUCTION}

Global trade in phytopharmaceuticals has continued to increase. The total global market of plant-based drugs was estimated at US\$ 18 billion in 2005 [1]. Similarly, Pakistani communities are well aware of the therapeutic potentials of medicinal plants. Unfortunately, these phytomedicines are used on the basis of empirical knowledge that has been transmitted from generation to generation without scientific basis. World Health Organization (WHO) has recommended that such plants should be evaluated for their efficacy, potency and safety [2].

The Gloriosa superba Linn is commonly known as climbing lily (English) and Samp ki Botee (Urdu, Pakistani) and belongs to Colchicaceae family. It is native to tropical Africa but is now also found growing naturally throughout tropical Asia, including India, Sri Lanka, Malaysia and Burma [3]. In traditional practice, it is used as a source of colchicine [4]. The juice of the leaves is used to kill head lice and also as an ingredient in arrow poisons, as well as mosquito killer, wound healing agent $[4,5]$. The crude extract and its soluble fractions have displayed significant antibacterial and lipoxygenase activities $[6,7]$.

Phytochemically, in addition to colchiconiod alkaloids, G. superba also contains chelidonic acid, salicylic acid, phytosterils, stigmasterin and $\beta$-sistosterol glycoside [4]. The present study was aimed to evaluate the presence and quantity of metallic elements in different parts of $G$. superba collected from two different locations in Pakistan.

\section{EXPERIMENTAL}

\section{Plant material}

The whole plant of $G$. superba Linn was collected from two different locations of Chatter Bagh, Islamabad (Pakistan) during the month of June 2007. Authentication of the plant materials was done by Mr. Shahid Farooqi, Principal Scientific Officer, Department of Botany, Pakistan Council for Scientific and Industrial Research (PCSIR) Laboratories, Peshawar, Pakistan. A voucher specimen with catalogue no. 5689 (PES) was deposited in the herbarium of the organization. The shade-dried plant material rhizomes, leaves, stems and flowers - were chopped into small pieces and then pulverized into fine powder. The powdered material was dried for $30 \mathrm{~min}$ at $60^{\circ} \mathrm{C}$ in an oven and stored carefully in dry clean polythene bags.

\section{Sample analysis}

The samples were prepared following a standard protocol [8]. Dry ashing of the plant material was carried out by placing $1 \mathrm{~g}$ of the test material in a pre-weighed porcelain crucible and igniting for $24 \mathrm{~h}$ at a temperature not exceeding $500^{\circ} \mathrm{C}$ in a muffle furnace. The ashed sample was transferred to a beaker containing $10 \mathrm{~mL}$ of $20 \%$ extra pure grade $\mathrm{HCl}$ and was digested in a water bath for $20 \mathrm{~min}$. The resulting solution was filtered through an ultra-filter membrane of $0.8 \mu \mathrm{m}$ pore diameter. It was diluted to $100 \mathrm{~mL}$ with deionized water. The samples were analyzed in triplicate by flame atomic absorption spectrophotometer (Polarized Zeeman Hitachi 2000) and flame photometer (Jenway PFP7, UK). The reference metals were obtained from Merck (Darmstadt, Germany). Calibration standards of each metal were prepared by appropriate dilution of the stock solutions. All the chemicals used in the study were of analytical reagent grade.

\section{Data analysis}

Data were presented as mean $\pm \operatorname{SEM}(n=3)$. The statistical analysis was done using GraphPad, San Diego, CA, USA). 


\section{RESULTS}

The results for the levels of micronutrients are presented in Table 1. High accumulation of different nutrients were found in samples collected from the polluted area. $\mathrm{Zn}$ and Fe were within permissible limits, i.e., 13.4 25.0 and 3.3 - $17.7 \mathrm{ppm}$ respectively. However, the metal contents exceeded permissible limits. For example, $\mathrm{Cu}$ concentration was $11.3,13.0,10.9,7.5$ and $9.6 \mathrm{ppm}$ in rhizome, leaf, stem, flower and soil, respectively. Similarly high concentrations were observed for $\mathrm{Cr}$ and $\mathrm{Ni}$. The values for micronutrients in the sample collected from the unpolluted area, however, were mostly within permissible range with a few exceptions. However, significant concentration of $\mathrm{Zn}(3.5-27.9 \mathrm{ppm})$ and $\mathrm{Fe}$ (14.5- $21 \mathrm{ppm})$ were recorded.

The results for the macronutrient contents of the materials are listed in Table 2. Samples collected from both polluted and unpolluted areas, including soil, showed high levels of $\mathrm{Ca}, \mathrm{Na}$ and $\mathrm{K}$.

\section{DISCUSSION}

The particular metal content of a plant is a function of its uptake capacity, as well as a combination of metal species in solution, sorption equilibria at the solid-liquid phase interface in the vicinity of the plant roots and intracellular binding states [9]. Plants also have an affinity to take up some metal ions that are not linked directly to their endurance, e.g., Cd, Co and Ag [10].

\section{Micronutrients}

Zinc is classified as one of the most abundant indispensable micronutrients. It is found in almost all body tissues [11] and acts as antiinflammatory, antioxidant, bone resorptive, as well as important for cell signaling, release of hormones and in apoptosis. Zinc deficiency in human mostly occurs in pregnancy [11] and is characterized by growth failure, impaired parturition (dystocia), neuropathy, decreased cyclic food intake, diarrhoea, dermatitis, hair

Table 1: Metallic contents (ppm) of samples collected from polluted and unpolluted areas

\begin{tabular}{lllllll}
\hline Metal & Rhizome & Leaf & Stem & Flower & Soil & Permissible limit (ppm) \\
\hline \multicolumn{2}{l}{ Polluted area } & & & & & \\
$\mathrm{Zn}$ & $25.0 \pm 0.3$ & $13.4 \pm 0.0$ & $14.1 \pm 0.0$ & $\mathrm{ND}$ & $10.8 \pm 0.0$ & $50[21]$ \\
$\mathrm{Cu}$ & $11.3 \pm 0.3$ & $14.8 \pm 0.0$ & $10.9 .4 \pm 0.0$ & $7.5 \pm 0.2$ & $9.6 \pm 0.1$ & $10[21]$ \\
$\mathrm{Cr}$ & $1.5 \pm 0.0$ & $1.7 \pm 0.1$ & $1.7 \pm 0$ & $1.4 \pm 0.0$ & $1.9 \pm 0.0$ & $1.5[21]$ \\
$\mathrm{Fe}$ & $17.7 \pm 0.1$ & $14.3 \pm 2.0$ & $17.2 \pm 0.5$ & $3.3 \pm 0.02$ & $11.6 \pm 1.6$ & $36-241[10]$ \\
$\mathrm{Mn}$ & $13.5 \pm 0.3$ & $11.0 \pm 0.7$ & $10.8 \pm 0.0$ & $7.7 \pm 0.4$ & $7.2 \pm 0.6$ & $200[21]$ \\
$\mathrm{Ni}$ & $2.0 \pm 0.1$ & $0.8 \pm 0.0$ & $1.7 \pm 0.0$ & $0.3 \pm 0.0$ & $1.3 \pm 0.0$ & $1.5[21]$ \\
$\mathrm{Pb}$ & $\mathrm{ND}$ & $\mathrm{ND}$ & $\mathrm{ND}$ & $\mathrm{ND}$ & $\mathrm{ND}$ & $10[11]$ \\
$\mathrm{Cd}$ & $\mathrm{ND}$ & $\mathrm{ND}$ & $\mathrm{ND}$ & $\mathrm{ND}$ & $\mathrm{ND}$ & $0.3[11]$ \\
$\mathrm{Co}$ & $\mathrm{ND}$ & $\mathrm{ND}$ & $\mathrm{ND}$ & $\mathrm{ND}$ & $\mathrm{ND}$ & $0.2[21]$ \\
$\mathrm{Unpolluted}$ area & & & & & \\
$\mathrm{Zn}$ & $27.9 \pm 0.6$ & $18.8 \pm 0.1$ & $16.6 \pm 0.0$ & $3.5 \pm 0.0$ & $11.2 \pm 0.1$ & $50[21]$ \\
$\mathrm{Cu}$ & $9.5 \pm 0.1$ & $8.3 \pm 0.2$ & $10.2 \pm 0.0$ & $3.5 \pm 0.1$ & $5.0 \pm 0.0$ & $10[21]$ \\
$\mathrm{Cr}$ & $1.1 \pm 0.1$ & $1.6 \pm 0.0$ & $1.5 \pm 0.0$ & $1.0 \pm 0.0$ & $0.6 \pm 0.0$ & $1.5[21]$ \\
$\mathrm{Fe}$ & $18.7 \pm 0.1$ & $16.2 \pm 0.9$ & $21.0 \pm 0.0$ & $14.5 \pm 0.05$ & $12.2 \pm 0.1$ & $36-241[10]$ \\
$\mathrm{Mn}$ & $14.7 \pm 0.9$ & $13.6 \pm 0.7$ & $10.4 \pm 0.1$ & $9.1 \pm 0.1$ & $9.1 \pm 0.5$ & $200[21]$ \\
$\mathrm{Ni}$ & $0.8 \pm 0.0$ & $1.6 \pm 0.0$ & $0.6 \pm 0.0$ & $0.6 \pm 0.1$ & $0.4 \pm 0.1$ & $1.5[21]$ \\
$\mathrm{Pb}$ & $\mathrm{ND}$ & $\mathrm{ND}$ & $\mathrm{ND}$ & $\mathrm{ND}$ & $\mathrm{ND}$ & $10[11]$ \\
$\mathrm{Cd}$ & $\mathrm{ND}$ & $\mathrm{ND}$ & $\mathrm{ND}$ & $\mathrm{ND}$ & $\mathrm{ND}$ & $0.3[1]$ \\
$\mathrm{Co}$ & $\mathrm{ND}$ & $\mathrm{ND}$ & $\mathrm{ND}$ & $\mathrm{ND}$ & $\mathrm{ND}$ & $0.2[21]$ \\
\hline $\mathrm{Da}$ & $\mathrm{ND}$ &
\end{tabular}

Data are expressed as the mean \pm SEM $(n=3) ; N D=$ not detected 
Khan et al

Table 2: Metallic contents (ppm) of samples collected from polluted and unpolluted areas

\begin{tabular}{lllllll}
\hline Metal & Rhizome & Leaf & Stem & Flower & Soil & Permissible limit (ppm) \\
\hline Polluted area & & & & & \\
$\mathrm{Ca}$ & $45.7 \pm 0.3$ & $50.0 \pm 1.0$ & $37.0 \pm 1.0$ & $32.0 \pm 1.5$ & $24.0 \pm 0.9$ & $44-614[10]$ \\
$\mathrm{Na}$ & $34.8 \pm 1.0$ & $40.0 \pm 1.5$ & $45.0 \pm 1.4$ & $45.0 \pm 1.1$ & $50.0 \pm 1.7$ & $2610-51340[10]$ \\
$\mathrm{K}$ & $126.0 \pm 1.5$ & $120.0 \pm 2.5$ & $125.0 \pm 2.0$ & $50.0 \pm 0.9$ & $42.0 \pm 1.9$ & $6380-36,600[10]$ \\
Unpolluted area & & & & & \\
$\mathrm{Ca}$ & $43.4 \pm 0.4$ & $56.0 \pm 0.1$ & $39.0 \pm 0.2$ & $30.0 \pm 1.10$ & $24.0 \pm 0.6$ & $44-614[10]$ \\
$\mathrm{Na}$ & $44.6 \pm 1.0$ & $40.0 \pm 1.5$ & $47.0 \pm 0.1$ & $44.6 \pm 1.02$ & $50.0 \pm 1.7$ & $2610-51340[10]$ \\
$\mathrm{K}$ & $149.4 \pm 1.7$ & $139.0 \pm 0.1$ & $121.0 \pm 1.0$ & $50.0 \pm 0.9$ & $42.0 \pm 1.9$ & $6380-36,600[10]$ \\
\hline \multicolumn{5}{l}{ Data are expressed as mean $\pm \mathrm{SEM}(n=3)$}
\end{tabular}

loss, bleeding tendency, hypotension, seizers and hypothermia. Acute zinc toxicity causes abdominal pain, nausea, vomiting and diarrhoea. Chronic exposure to zinc also contributes to copper deficiency $[13,14]$. The plant material collected from both locations possessed significant concentration of $\mathrm{Zn}$ which was within the permissible limit (50 $\mathrm{ppm}$ ) and, therefore, can be regarded as a potential source of $\mathrm{Zn}$.

Copper is an essential element for plants and animals. It is crucial for various human metabolic systems. Inside the body, it regulates various biological systems including oxidation-reduction reaction, energy production, connective tissue formation, iron metabolism, neurotransmitter synthesis, etc. The most common sources for copper distribution in soils are pesticides, fertilizers, industry and sewage sludge. Melting, grinding or cutting of copper may produce fumes or dust, and exposure or inhalation of these fumes is a health hazard. $\mathrm{Cu}$ toxicity can cause kidney and liver damage [13]. The samples collected from the polluted area exceeded the permissible limit for plants (10 ppm). However, the plant samples collected from the unpolluted area was within limits. The cause of the difference in $\mathrm{Cu}$ levels was the 3-fold higher level in polluted soil.

Chromium plays a vital role in the biosynthesis of fatty acids and cholesterols, metabolism of carbohydrates, proteins, lipids, and has been shown to facilitate the action of insulin [14]. For this reason, Cr-based supplements are used for weight loss [14].
The permissible limit for $\mathrm{Cr}$ in plants is 1.5 ppm. Cr toxicity is associated with chromium exposure are skin rashes, stomach upset, ulcers, respiratory problems, weakened immune systems, kidney and liver damage, alteration of genetic material, lung cancer and ultimately death. Plant samples collected from the polluted area exceeded permissible limits in majority of cases. Samples from the unpolluted area were within limits. Based on the data obtained, the high level of $\mathrm{Cr}$ in the plant materials from the polluted area is as a result of the elevated levels of the metallic element of $\mathrm{Cr}$ in the soil.

Iron is the most abundant essential micronutrient in body tissues. Optimal Fe concentration is required for the endurance of plants, animals and microorganisms [13]. WHO has reported that approximately $46 \%$ of the world's children and $48 \%$ of pregnant women suffer from anemia. Fe deficiency causes irreversible alteration of brain functions and affects immune response in many ways $[15,16]$. Significant concentrations of Fe were found in almost all the tested samples collected from both areas. None of the samples crossed the permissible limit and therefore, the plant is a suitable natural source of iron.

Manganese is an essential metallic element for both plant and animal growth. $\mathrm{Mn}$ intoxication leads to Parkinsonism which usually is progressive and irreversible, reflecting to some extent the permanent damage of neurologic structures [17]. The permissible limit in plants is 200 ppm. 
Samples (including soil) from both polluted and unpolluted areas showed $\mathrm{Mn}$ content within permissible limit.

Nickel is naturally present in the earth's crust. Natural nickel deficiency does not occur as it is abundantly present in all types of food. Nickel-related vulnerabilities include skin allergies, lung fibrosis, variable degrees of kidney and cardiovascular system poisoning, and stimulation of neoplastic transformation [11]. Nickel is mostly present in the pancreas and plays an important role in the production of insulin. Nickel deficiency causes liver disorders [13]. The permissible limit of $\mathrm{Ni}$ in plants is $1.5 \mathrm{ppm}$. Our findings revealed nickel levels were within limit except for the plant rhizome from the polluted area which had a a level that exceeded the limit.

\section{Macronutrients}

Calcium is a vital macronutrient and, along with phosphorus, is a structural component of bones, teeth, and soft tissues [18]. Binding of $\mathrm{Ca}^{2+}$ on the surface of human growth hormone provides considerable thermodynamic stability to protein by changing the secondary structure of the protein [13]. Regulatory functions of $\mathrm{Ca}$ include monitoring of muscle and nerve functions, glandular secretions, and blood vessel dilation and contraction. Ca deficiency is responsible for weakness of bone which then becomes more prone to fracture. Deficiency can also produce skeletal muscle spasm and abnormality in heart beat that may cause heart failure.

The test samples from both locations exhibited $\mathrm{Ca}$ levels that were within the recommended range for plants. According to the Food and Nutrition Board [20], the recommended daily intake of $\mathrm{Ca}$ is 1000 $\mathrm{mg} /$ day. Thus, the plant species is a rich source of dietary Ca.

Sodium is a critically important macronutrient in the human body. a common dietary source of sodium is table salt $(\mathrm{NaCl})$. In humans, it is essential for the maintenance of normal physiology. An adequate intake of sodium is required for optimal growth, and is the predominant cation in the extracellular fluid; either a deficiency or excess of sodium will alter overall fluid balance and distribution [13]. Na deficit is exemplified by mood changes, muscle cramps, fatigue, hair loss, hypotension and dehydration [13]. We observed marked concentration of $\mathrm{Na}$ in various samples collected from both locations however the $\mathrm{Na}$ concentration in the test samples not exceeded the permissible limit as shown in table 2 . The recommended daily intake of $\mathrm{Na}$ is 1-3.8 mg/day [13]. The adverse effect of the high concentration of $\mathrm{Na}$ is hypertension.

Potassium is a useful macronutrient in humans. $\mathrm{K}^{+}$plays a vital role in the regulation of action potentials and intercellular signaling in electrically active cells. In both excitable and non-excitable cells, $\mathrm{K}$ channels regulate various functions, including regulation of membrane potential, signal transduction, insulin secretion, hormone release, regulation of vascular tone, cell volume and immune response [13]. The average intake of potassium is $2300 \mathrm{mg} /$ day for adult women and $3100 \mathrm{mg} /$ day for adult men [13]. Our study showed that all the samples contained significant concentrations that did not, however, exceed the permissible limit.

\section{CONCLUSION}

Our study revealed the presence of significant concentrations of micro- and macro-nutrients in plant samples collected from both polluted and unpolluted areas. The levels of some metalallic elements, including $\mathrm{Cr}, \mathrm{Ni}$ and $\mathrm{Cu}$ in samples collected from polluted area, however, exceeded permissible limits. Excessive levels of these metals in medicinal plants could lead to longterm health complications in humans, and could even be lethal. It is important, therefore, that adequate safety evaluation of medicinal plant, including determination of 
heavy metal content, be carried out prior to formulation into finished medicines.

\section{REFERENCES}

1. Saklani A, Kutty S. Plant-derived compounds in clinical trials. Drug Discovery Today 2008; 13: 161-171.

2. Saeed M, Muhammad N, Khan $H$, Zakiullah. Assessment of hazardous heavy metals content of branded Pakistani herbal products. Trop J Pharm Res, 2011; 10: 499-506.

3. Chopra RN, Nayar SL, Chopra IC. Glossary of Indian medicinal plants. New Delhi: CSIR; 1956; $p$ 125-126.

4. Jana S, Shekhawat GS. Critical review on medicinally potent plant species: Gloriosa superba. Fitoterapia. 2011; 82: 293-301.

5. Chandra PK, Nehala F, Uppeandra D. Prioritization of medicinal plants on the basis of available knowledge, existing practices and use value status in Uttaranchal, India; Biodiversity Conservation. 2004; 13: 453-469.

6. Khan H, Ali Khan M, Hussain I. Enzyme inhibition activities of the extracts from rhizomes of Gloriosa superba Linn (Colchicaceae). J Enz Inhib Med Chem. 2007, 22: 722-725.

7. Khan $H$, Khan MA, Mahmood T. Antimicrobial activities of Gloriosa superba Linn extracts. J Enzyme Inhib Med Chem. 2008; 6: 855-859.

8. Khan MA, Ahmad I, ur Rahman I. Effect of Environmental Pollution on Heavy Metals Content of Withania Somnifera. J Chinese Chem Soc, 2007; 54: 339-343.

9. Clemens, S., M.G. Palmgren and U. Kramer. A long way ahead: understanding and engineering plant metal accumulation. Trends in Plant Sci, 2002; 7: 309-314.

10. Ajasa A, Bello M, Ibrahim A, Ogunwande I, Olawore $N$. Heavy trace metals and macronutrients status in herbal plants of Nigeria. Food Chem. 2004; 85:67-71.
11. Saeed $M$, Muhammad $N$, Khan $H$, Khan SA. Analysis of toxic heavy metals in branded Pakistani herbal products. J Chem Soc Pak. 2010; 32: 471-475.

12. Anonymous. Drug Information. Herbal Medicines. World Health Organization, Geneva, 2002; $p$ 16.

13. Saeed $M$, Khan $H$, Khan $M$, Khan $F$, Khan $S A$, Muhammad N: Quantification of various metals and cytotoxic profile of aerial parts of Polygonatum verticillatum. Pak J Bot. 2010; 42: 3995-4002.

14. Lukaski H, Siders W, Penland J. Chromium picolinate supplementation in women: effects on body weight, composition, and iron status. Nutrition. 2007; 23: 187-195.

15. Beard JL. Iron biology in immune function, muscle metabolism and neuronal functioning. J Nutri 2001; 131: 568S-579S.

16. James DC. Diagnosis and management of iron deficiency anemia. Best Practice Res Clin Haematol, 2005; 18: 319-332.

17. Wang $D, D u X$, Zheng W. Alteration of saliva and serum concentrations of manganese, copper, zinc, cadmium and lead among career welders. Toxicol Lett. 2008; 176: 40-47.

18. Shapiro R, Heaney RP. Co-dependence of Calcium and Phosphorus for growth and bone development under conditions of varying deficiency. Bone, 2003; 32: 532-540.

19. Morris $M, N a$, Johnson A. Salt craving: The psychobiology of pathogenic sodium intake. Physiol Behav. 2008; 94: 709-721.

20. IOM. Dietary reference intakes for vitamin $A$, vitamin K, Boron, Chromium, Copper, lodine, Iron, Manganese, Molybdenum, Nickel, Silicon, Vanadium, and Zinc. Washington D.C: National Academy Press; 2001; pp 290-442.

21. Srivastava SK, Rai V, Srivastava M, Rawat AKS, Mehrotra S. Estimation of heavy metals in different Berberis species and its market samples. Environ Monit Assess. 2006; 116: 315-320. 